\title{
Presença de anticorpos anti-BoHV-1 em rebanhos caprinos de São Paulo e Minas Gerais
}

\author{
Bruna Alexandrino ${ }^{1}$ \\ Lucimara Antônio Borges ${ }^{1}$ \\ José Roberto Ferreira Alves Júnior ${ }^{1}$ \\ Fabio Carvalho Dias ${ }^{2}$ \\ Ingrid Bortolin Affonso ${ }^{1}$ \\ Mônica Costa Oliveira ${ }^{1}$ \\ Maria da Glória Buzinaro ${ }^{1}$ \\ Samir Issa Samara ${ }^{1 *}$
${ }^{1}$ Departamento de Medicina Veterinária Preventiva e Reprodução Animal, FCAV, UNESP
Via Paulo Donato Castellane s/n, CEP 14884-900, Jaboticabal - SP, Brasil
${ }^{2}$ Coordenadoria de Defesa Agropecuária do Estado de São Paulo, Campinas - SP, Brasil
* Autor para correspondência
samara@fcav.unesp.br

Submetido em $12 / 07 / 2012$

Aceito para publicação em 25/02/2013

\section{Resumo}

Esta pesquisa avaliou a presença de anticorpos contra o herpesvírus bovino tipo 1 (BoHV-1) em amostras de soro de caprinos. Desse modo, foram analisadas 337 amostras provenientes de 5 propriedades, sendo 2 localizadas no estado de Minas Gerais, e as outras 3 no estado de São Paulo. As amostras foram submetidas ao teste de virusneutralização com estirpe viral Nebraska, para verificar a presença de anticorpos contra o BoHV-1. Apesar de ter sido de 3 a média geométrica dos títulos dos anticorpos, a ocorrência de reatividade nos animais foi de $62 \%$ (209/337), sendo positivas $57,2 \%$ (151/264) das amostras advindas das propriedades localizadas no estado de Minas Gerais e 79,5\% (58/73) para as amostras do estado de São Paulo. Devido ao fato de os caprinos não constituírem uma espécie-alvo desse vírus, a alta ocorrência de anticorpos anti-BoHV-1 desperta um alerta epidemiológico em rebanhos consorciados, fato que direciona a necessidade de maiores estudos para mostrar a importância da infecção nessa espécie animal.

Palavras-chave: BoHV-1; CpHV-1; Herpesvírus; Sorologia; Virusneutralização

\section{Abstract}

Presence of anti-BoHV-1 antibodies in caprine herds from Sao Paulo and Minas Gerais, Brazil. This research evaluated the presence of antibodies against the bovine herpesvirus type 1 (BoHV-1) in serum samples from caprines. This way, one analyzed 337 samples from 5 properties, 2 of them located at the state of Minas Gerais and the other 3 at the state of Sao Paulo. The samples underwent the virusneutralization test using the Nebraska viral strain, in order to verify the presence of antibodies against BoHV-1. Despite the geometric mean of antibody titers was 3, the occurrence of reactivity in animals achieved $62 \%(209 / 337)$, being positive $57.2 \%$ 
(151/264) of samples from the properties at the state of Minas Gerais and 79.5\% (58/73) of samples from the state of Sao Paulo. Due to the fact that caprines don't constitute a target species of this virus, the high occurrence of anti-BOHV-1 antibodies awakens an epidemiological alert on consortium herds, a fact driving the need for further studies to show the importance of infection in this animal species.

Key words: BoHV-1; CpHV-1; Herpesvirus; Serology, Virusneutralization

\section{Introdução}

O herpesvírus bovino tipo 1 (BoHV-1) assim como o herpesvírus caprino tipo 1 (CpHV-1) são vírus da família Herpesviridae, subfamília Alphaerpesvirinae (FENNER, 1987), gênero Varicellovirus. O curso das enfermidades desencadeadas por esses vírus é rápido e se resolve em cinco a 10 dias quando não ocorrem infecções bacterianas secundárias; mesmo assim com taxa de letalidade normalmente baixa (KAHRS, 1977). De modo geral, as infecções por esses vírus causam problemas respiratórios e mais comumente desordens no sistema reprodutivo desencadeando aborto, infertilidade temporária e retorno de cio (HORNER et al., 1982; RIET-CORREA et al., 1996; WILLIAMS et al., 1997; FRANCO; ROEHE, 2007). Já em caprinos recém-nascidos, o $\mathrm{CpHV}-1$ causa severa infecção generalizada, afetando principalmente o trato digestivo e frequentemente levando a morte (SAITO et al., 1974; METTLER et al., 1979); porém nos animais adultos a doença geralmente é subclínica (FRANCO; ROEHE, 2007). Contudo, as grandes perdas econômicas tanto para o BoHV-1 quanto para o CpHV-1 se deve mesmo ao impacto sobre a esfera reprodutiva (THIRY et al., 2008).

O BoHV-1 está amplamente distribuído em rebanhos bovinos de praticamente todo o mundo, tendo o Brasil uma prevalência alta nessa espécie, porém a infecção natural também ocorre em caprinos, ovinos, suínos e em algumas espécies selvagens como cervo (WYLER et al., 1989), fato pouco relatado. De forma experimental, esse agente pode infectar coelhos e cobaias (guinea pigs) (MEYER et al., 1996). Apesar dos caprinos se infectarem naturalmente pelo BoHV-1 muito pouco se sabe sobre o que este vírus pode causar de fato nessa espécie animal.

No caso do CpHV-1, o primeiro relato foi um caso de enterite em caprinos no Estado da Califórnia, que ocorreu em 1975 (SAITO et al., 1974). Contudo a distribuição desta enfermidade não tem sido muito estudada, porém há relatos de $50 \%$ de prevalência na Grécia (KOPTOPOULOS et al., 1988), 21\% na Espanha (KEUSER et al., 2004) e de 30 a 60\% na Itália (TEMPESTA et al., 1994; GUERCIO et al., 1998; THIRY et al., 2006a). Há ainda relatos pelo CpHV-1 na Autrália, Nova Zelândia, Canadá, Estados Unidos e em vários países europeus (FRANCO; ROEHE, 2007), no entanto sem apresentação de dados sistematizados.

As principais portas de entrada para o $\mathrm{CpHV}-1$ são as mucosas genital, ocular ou orofaríngea. $\mathrm{Na}$ infecção natural pelo CpHV-1 a doença se apresenta frequentemente de forma subclínica podendo evoluir para uma infecção latente (ENGELS et al., 1992); assim como ocorre no BoHV-1 (LEMAIRE et al, 1994). Na infecção primária, anticorpos neutralizantes são detectados por volta de uma a duas semanas pósinfecção, atingindo maiores títulos entre a terceira e quarta semana, sendo que este decresce lentamente por volta de seis a dez meses (título entre 4 e 8) (TEMPESTA et al., 2005).

A infecção natural pelo $\mathrm{CpHV}-1$ foi relatada em cabras e em espécies silvestres, como cervídeos, no entanto, ovinos e bovinos mostraram-se suscetíveis em infecção experimental (BERRIOS et al., 1975; PAPANASTOPOULOU et al., 1991) existindo também a possibilidade do estabelecimento de infecção latente em bovinos, do mesmo modo como ocorre com BoHV-1 em caprinos (FRANCO; ROEHE, 2007). No Brasil são escassos os estudos sobre o CpHV-1 e o BoHV-1em caprinos, sendo assim, este trabalho teve como objetivo avaliar a ocorrência de anticorpos para o BoHV-1 na espécie caprina.

\section{Material e Métodos}

Com o intuito de pesquisar a ocorrência de anticorpos contra o herpesvírus bovino na espécie 
caprina foram avaliadas 337 amostras de soros de caprinos provenientes de propriedades localizadas no sul do Estado de Minas Gerais e nordeste do Estado de São Paulo. Das amostras testadas, 36 foram obtidas de caprinos da propriedade situada no município de Itamogi (A) e 228 de Monte Santo de Minas (B), ambas pertencentes ao Estado de Minas Gerais. Do Estado de São Paulo foram testadas 30 amostras de caprinos de uma propriedade do município de Ipiguá (C), 19 de Paulo de Faria (D) e 24 de Poloni (E). Das propriedades analisadas, apenas na B foram constatados problemas reprodutivos como aborto e retorno de cio.

Todos os caprinos testados tinham no mínimo quatro meses de idade para evitar a interferência de anticorpos colostrais. Foram colhidas amostras de sangue em tubos vacutainer sem anticoagulante por punção da veia jugular de machos e fêmeas. As alíquotas de soro foram colocadas em microtubos e armazenadas em freezer com temperatura de $-20^{\circ} \mathrm{C}$ até o momento do processamento laboratorial.

As amostras foram testadas em duplicata pela técnica de vírus-neutralização (VN) como preconizado pela Organização Mundial de Saúde Animal (OIE), que considera reagente a amostra de soro capaz de neutralizar a infecção das células a partir da diluição 1:2 (OIE, 2011). Antes de sua utilização, as amostras de soro foram inativadas em banho-maria, à temperatura de $56^{\circ} \mathrm{C}$, por um período de $30 \mathrm{~min}$, para inativação do sistema complemento. Foi utilizada suspensão viral com 200TCID (Tissue Cell Infectious Dose) da estirpe do BoHV-1 denominada Nebraska e suspensão de célula Madin \& Darby Bovine Kidney (MDBK), na concentração de $3 \times 10^{5}$ céls $/ \mathrm{mL}$. Esta técnica apresenta boa sensibilidade e especificidade cujo princípio melhor se assemelha à neutralização de vírus por anticorpos que ocorre in vivo (FLORES, 2007).

O título de anticorpos neutralizantes foi expresso como a recíproca da última diluição de soro capaz de impedir o característico efeito citopático causado pelo vírus, sendo o seu valor o inverso da diluição e o título final foi resultante da média geométrica dos títulos encontrados nas duplicatas (GMT) (THRUSFIELD, 1986).

Esta pesquisa foi aprovada pelo Comitê de Ética e Bem-Estar Animal da Faculdade de Ciências Agrárias e Veterinárias, UNESP, câmpus de Jaboticabal, número de protocolo 019456/09.

\section{Resultados}

Das amostras de soro testadas, 62\% (209/337) foram positivas para o BoHV-1. A taxa de positividade observada nas amostras de soro provenientes do Estado de Minas Gerais foi de 57,2\% (151/264), sendo que os animais da propriedade A apresentaram 88,9\% (32/36) de positividade e os da propriedade B apresentaram 52,2\% (119/228). Para os animais provenientes do Estado de São Paulo, a prevalência observada foi de 79,5\% (58/73), sendo $86,7 \%$ (26/30) na propriedade C, 63,1\% (12/19) na propriedade D e $83,3 \%(20 / 24)$ na propriedade E.

A GMT das amostras positivas foi três em quase todas as propriedades, exceto na A, cuja GMT foi quatro. Analisando-se as GMT das amostras de soro de cada propriedade observam-se os valores 16 na A, 64 na $\mathrm{B}$, oito na $\mathrm{C}$, quatro na $\mathrm{D}$ e quatro na $\mathrm{E}$. Os dados encontram-se apresentados na Tabela 1.

TABELA 1: Média geométrica dos títulos de anticorpos neutralizantes contra BoHV-1 em amostras de soro de caprinos.

\begin{tabular}{|c|c|c|c|c|c|}
\hline Estado & Propriedades & Reagentes/total & $\%$ & Distribuição dos títulos de anticorpos neutralizantes $_{b}$ & GMT \\
\hline Minas & $\mathrm{A}$ & $32 / 36$ & 88,9 & $<2(4), 2(11), 4(10), 8(10), 16(1)$ & 4 \\
\hline Gerais & $\mathrm{B}$ & $119 / 228$ & 52,2 & $<2(109), 2(67), 4(30), 6(3), 8(8), 11(3), 16(3), 23(1), 32(3), 64(1)$ & 3 \\
\hline Subtotal & $\mathrm{A}+\mathrm{B}$ & $151 / 264$ & 57,2 & & 3 \\
\hline \multirow{3}{*}{$\begin{array}{c}\text { São } \\
\text { Paulo }\end{array}$} & $\mathrm{C}$ & $26 / 30$ & 86,7 & $<2(4), 2(13), 4(9), 8(4)$ & 3 \\
\hline & $\mathrm{D}$ & $12 / 19$ & 63,1 & $<2(7), 2(7), 4(5)$ & 3 \\
\hline & $\mathrm{E}$ & $20 / 24$ & 83,3 & $<2(4), 2(11), 4(9)$ & 3 \\
\hline Subtotal & $\mathrm{C}+\mathrm{D}+\mathrm{E}$ & $58 / 73$ & 79,5 & & 3 \\
\hline Total & & $209 / 337$ & 62 & & 3 \\
\hline
\end{tabular}

(a) Foram consideradas positivas amostras que apresentaram títulos de anticorpos neutralizantes $\geq 2$; (b) Título de anticorpos neutralizantes (número de amostras que apresentaram este título); (c) Média geométrica dos títulos dos anticorpos neutralizantes contra BoHV-1, nas diferentes localidades analisadas. 


\section{Discussão}

Como pode ser observado, a ocorrência de anticorpos do BoHV-1 em amostras de soro de caprinos foi elevada $(62 \%, 209 / 337)$, porém a maior GMT (4) foi observada na propriedade A. Apesar da possibilidade de infecção natural pelo BoHV-1 em caprinos (PAPANASTOPOULOU et al., 1991), há poucos relatos da pesquisa desse anticorpo na espécie citada.

A literatura pertinente mostra que a prevalência do CpHV-1 em muitos países é alta, como na Grécia com $50 \%$, (KOPTOPOULOS et al., 1988), Itália entre 30\% e 60\% (TEMPESTA et al., 1994; GUERCIO et al., 1998; THIRY et al., 2006b) e Espanha 21\% (KEUSER et al., 2004). Em relação à presença do BoHV-1 em caprinos, estudo realizado na província de Van, Turquia, encontrou uma prevalência de $0,7 \%$ (3/407) (ATAVESEN et al., 2010). Outra pesquisa realizada em 12 províncias do Egito, onde foram colhidas amostras de 1600 caprinos e ovinos, examinados pelo teste de ELISA, obteve-se uma prevalência de 27,6\% em caprinos (MAHMOUD; AHMED, 2009). No Estado de Tamil Nadu, Índia, 67 amostras de soro de caprinos sem doença clínica, colhidas em um abatedouro, foram analisadas pelo teste de hemaglutinação que detectou $32,2 \%$ de reatividade sendo que o menor título foi oito (RAJARAMAN et al., 1994).

No presente trabalho, houve a predominância de títulos baixos, tendo apenas um animal da propriedade B apresentado título elevado (64). Títulos baixos podem ser indicativos de infecção recente, quando o animal se encontra na primeira ou segunda semana pós-infecção, ou tardia, dez meses pós-infecção (TEMPESTA et al., 2005). Em pesquisa realizada com reativação da infecção viral, não foi possível induzir em caprinos títulos maiores que oito (TEMPESTA et al., 2002).

Das cinco propriedades onde foi feita a presente pesquisa, em apenas uma (B) havia relatos de desordens na esfera reprodutiva e justamente nela foram encontrados os maiores títulos de anticorpos individuais. Os soros dos animais provenientes dessa propriedade foram submetidos também aos exames para detecção de anticorpos contra Toxoplasma gondii, Leptospira spp. e
Brucella melitensis resultando em negativas para todas as análises, fato bastante indicativo de que as possíveis desordens reprodutivas possam estar associadas a infecção pelo BoHV-1 ou CpHV-1.

Pelo fato do BoHV-1 poder infectar a espécie caprina há fortes indícios de que esse vírus pode estar acometendo os caprinos nas regiões estudadas, tanto pela alta ocorrência como pelas falhas reprodutivas destacadas nos animais de uma das propriedades. Porém é importante continuarem as investigações, pois a metodologia empregada nesta pesquisa não descarta a possibilidade de haver infecção cruzada com o BoHV-1, necessitando o uso de técnicas mais aprofundadas para realmente determinar qual o vírus está presente nessas propriedades.

Vale salientar que há ainda a necessidade de maiores estudos sobre o BoHV-1 na espécie caprina para elucidar não só as causas desses problemas reprodutivos, mas principalmente se essa espécie animal é capaz de transmitir o vírus a outros animais, servindo de reservatório; ou ao se infectar, apenas adoece, porém sem eliminar o vírus para o ambiente ou eliminando uma quantidade insuficiente para infectar outros animais.

\section{Agradecimentos}

Os autores agradecem à Fundação de Apoio e Pesquisa do Estado de São Paulo (FAPESP) (Processo 2010/10399-0), ao CNPq (Processo 140363/2010-6), pelo financiamento desta pesquisa, e a Assistente de Suporte Acadêmico, Andréa Souza Ramos de Medeiros, pelo auxílio na execução das reações de VN.

\section{Referências}

ATASEVEN, V. S.; BASARAN, Z. Y.; DAGALP, S. B. Seroprevalence of parainfluenza virus-3 (PIV-3) and bovine herpesvirus type 1 (BHV-1) infections in goats of Van region [Turkish]. The Journal of the University of Yuzuncu Yil, Van, v. 21, n. 1, p. 7-9, 2010.

BERRIOS, P. E.; McKERCHER, D. G.; KNIGHT, H. D. Pathogenicity of a caprine herpesvirus. American Journal of Veterinary Research, Chicago, v. 36, p. 1763-1769, 1975.

ENGELS, M.; PALATINI, M.; METZLER, A. E.; PROBST, U.; KIHM, U.; ACKERMANN, M. Interactions of bovine and caprine 
herpesviruses with the natural and foreign hots. Veterinary Microbiology, Amsterdam, v. 33, n. 1-4, p. 69-78, 1992.

FENNER, F. Veterinary virology. 1 ed. Londres: Academic Press, 1987. $445 \mathrm{p}$.

FLORES, E. F. Diagnóstico laboratorial das infecções víricas. In: FLORES, E. F. (Ed.). Virologia Veterinária. Santa Maria: Editoraufsm, 2007. p. 295-326.

FRANCO, A. C.; ROEHE, P. M. Herpesviridae. In: FLORES, E. F. (Ed.). Virologia Veterinária. Santa Maria: Editoraufsm, 2007. p. 436-488.

GUERCIO, A.; GRECO, G.; LANIZOTO, G.; DI MARCO, V.; TODARO, M. Valutazione della diffusione di anticorpi anti Herpes Virus della capra in allevamenti caprini della Sicilia. Atti della Società Italiana di Patologia e di Allevamento degli Ovini e dei Caprini, Palermo, v. 12, p. 138-142, 1998.

HORNER, G. W.; HUNTER, R.; DAY, A. M. An outbreak of vulvovaginitis in goats caused by a caprine herpesvirus. New Zealand Veterinary Journal, Wellington, v. 30, p. 150-2, 1982.

KAHRS, R. F. Infectious bovine rhinotracheitis: a review and update. Journal of the American Veterinary Medical Association, Schaumburg, v. 171, n. 10, p. 1055-1064, 1977.

KEUSER, V.; ESPEJO-SERRANO, J.; SCHYNTS, F.; GEORGIN, J. P.; THIRY, E. Isolation of caprine herpesvirus type 1 in Spain. Veterinary Record, London, v. 154, p. 395-399, 2004.

KOPTOPOULOS, G.; PAPANASTASOPOULOU, M.; PAPADOPOULOS, O.; LUDWIG, H. The epizooliology of caprine herpesvirus (BHV-6) infectious in goat populations in Greece. Comparative Immunology, Microbiology and Infectious Diseases, Oxford, v. 11, p. 199-205, 1988.

LEMAIRE, M.; PASTORET, P. P.; TRIRY, E. Le contrôle de l'infection par lê vírus de lá rhinotrachéite infectieuse bovine. Annales de Médecine Vétérinaire, Bruxelles, v. 138, p. 167-180, 1994.

MAHMOUD, M. A.; AHMED, S. A. Prevalence of bovine herpesvirus-1 in sheep and goats in Egypt. Global Veterinaria, Giza, v. 3, n. 6, p.472-479, 2009.

METTLER, F.; ENGELS, M.; WILD, P.; BIVETTI, A. HerpesvirusInfektion bei Zicklein in der Schweiz. Schweizer Archiv für Tierheilkunde, Bern, v. 121, p. 655-662, 1979.

MEYER, G.; LEMAIRE, M.; LYAKU, J.; PASTORET, P. P.; THIRY, E. Stablishment of a rabbit model for bovine herpesvirus type 5 neurological acute infection. Veterinary Microbiology, Amsterdam, v. 51, n. 1-2, p.27-40, 1996.

OIE. Organização Mundial de Saúde Animal. 2011. Disponível em: <http://www.oie.int/fileadmin/Home/eng/Health_standards/ tahm/2.04.13 IBR IPV.pdf>. Acesso em: 13 abr. 2011.

PAPANASTASOPOULOU, M.; KOPTOPOULOS, G.; LEKKAS, S.; PAPADOPOULOS, O.; LUDWIG, H. An experimental study on the pathogenicity of the caprine herpesvirus type 1 (CHV1). Comparative Immunology, Microbiology and Infectious Diseases, Oxford, v. 14, p. 47-53, 1991.

RAJARAMAN, E. D.; APPAJIRAO, V. N.; BHAT, M. N.; DINAKARAN, A. M.; CHANDRASEKAR, V. Sero prevalence of BHV-1 antibodies in goats. Indian Veterinary Journal, Nova Deli, v. 71, n. 8, p. 757-759, 1994.

RIET-CORREA, F.; MOOJEN, V.; ROEHE, P. M.; WEIBLEN, R. Viroses confundíveis com Febre Aftosa: Revisão Bibliográfica. Ciência Rural, Santa Maria, v. 26, p. 323-332, 1996.

SAITO, J. K.; GRIBBLE, D. H.; BERRIOS, P. E.; KNIGHT, H. D.; Mc KERCHER, D. G. A new herpesvirus isolate from goats: preliminary report. American Journal of Veterinary Research, Chicago, v. 35, p. 847-848, 1974.

TEMPESTA, M.; CAVALLI, A.; VOIGT, V.; BUONAVOGLIA, D. Presenza di anticorpi per caprine herpesvirus 1 (CapHV.1) in allevament caprini dell'Italia meridionale. Atti della Società Italiana di Patologia e di Allevamento degli Ovini e dei Caprini, Palermo, v. 11, p. 121-122, 1994.

TEMPESTA, M.; GRECCO, G.; PRATELLI, A.; BUONAVOGLIA, D.; CAMERO, M.; MARTELLA, V. Reactivation of caprine herpesvirus 1 in experimentally infected goats. Veterinary Record, London, v. 4, p. 116-117, 2002.

TEMPESTA, M.; GRECCO, G.; TARSITANO, E.; THIRY, E.; CAMERO, M.; DECARO, N.; MARTELLA, V.; THIRY, E.; BUONAVOGLIA, C. Analysis of antibody response in goats to caprine herpesvirus 1. Biologicals, London, v. 33, p. 283-287, 2005. THIRY, J.; KEUSER, V.; SCHYNTS, F.; CHARTIER, C.; TEMPESTA, M.; ESPEJO-SERRANO, J.; SAEGERMAN, C.; THIRY, E. Evaluation de la prévalence sérologique de l'infection à herpèsvirus caprin 1 dans le sud-ouest de l'Europe. Épidémiologie et Santé Animale, Alfort, v. 49, p. 55-58, 2006a.

THIRY, J.; SAEGERMAN, C.; CHARTIER, P. M.; KEUSER, V.; THIRY, E. Serological of caprine herpesvirus 1 infection in Mediterranean France. Veterinary Microbiology, Amsterdam, v. 128, n. 3-4, p.261-268, 2008.

THIRY, J.; TEMPESTA, M.; CAMERO, M.; TARSIANO, E.; BELLACICCO, A. L.; THIRY, E.; BUONAVAGLIA C. A live attenuated glycoprotein $\mathrm{E}$ negative bovine herpesvirus 1 vaccine induces a partial cross-protection against caprine herpesvirus 1 infection in goats. Veterinary Microbiology, Amsterdam, v. 113, n. 3-4, p.303-308, 2006 b.

THRUSFIELD, M. V. Epidemiologia veterinária. 2. ed. São Paulo: Roca, 1986, 556 p.

WILLIAMS, N. M.; VICKERS, M. L.; TRAMONTIN, R. R.; PETRITES-MURPHY, M. B.; ALLEN, G. P. Multiple abortions associeted with caprine herpesvirus infection in goat herd. Journal of the American Veterinary Medical Association, Schaumburg, v. 211, n. 1, p. 89-91, 1997.

WYLER, R.; ENGELS, M.; SCHWYZER, M. Infectious bovine rhinotracheitis/vulvuvaginitis (BHV1). In: WITTMANN, G. (Ed.). Herpesvirus diseases of cattle, horses, and pigs. Boston/ Dordrecht/London: Kluwer Academic Publishers, 1989. p. 1-72. 